\title{
Проблемы сохранения старогородской жилой застройки города Хивы (на примере Дишан-Калы)
}

\author{
Г.С.Дурдиева, Хорезмская Академия Мамуна, Хива, Узбекистан \\ А.К.Заргаров, Хорезмская Академия Мамуна, Хива, Узбекистан \\ И.0.Рустамов., Хорезмская Академия Мамуна, Хива, Узбекистан \\ Ш.Дусчанов, Хорезмская академия Мамуна, Узбекистан
}

В статье приведены проблемы сохранения старой городской жилой застройки на территории Дишан-Кала города Хивы, отражающие различные этапы развития города, в том числе состояние традиционной жилой застройки. Эти проблемы были рассмотренны при разработке проектов реконструкции жилых домов на территории Дишан-Кала.

Ключевые слова: архитектура, жилая застройка, реконструкция, реставрация, памятники, исторические объекты.

Problems of Preserving the Old-Town Residential Buildings in the City of Khiva (on the Example of DishanKala)

G.S.Durdiev, Khorezm Mamun Academy, Khiva, Uzbekistan

A.K.Zargarov, Khorezm Mamun Academy, Khiva, Uzbekistan

I.0.Rustamov, Khorezm Mamun Academy, Khiva, Uzbekistan

Sh.Duschanov, Khorezm Mamun Academy, Khiva, Uzbekistan

The article presents the problems of preserving the old-town residential buildings of Khiva on the territory of Dishan-Kala reflecting various stages of the city's development, reflecting various stages of the city's development, including the state of traditional residential buildings. These problems were considered in the development of projects for the reconstruction of residential buildings on the territory of Dishan-Kala.

Keywords: architecture, residential, buildings, reconstruction, restoration, monuments, historical objects.

В городе Хиве исторически существовало традиционное разделение города на две обособленные друг от друга части: внутренний город Ичан-Кала и внешний город Дишан-Кала (рис. 1). В отличие от Ичан Калы, сохранившей свой внешний облик практически полностью, от внешних оборонительных стен остались только некоторые ворота, в частности, ворота Кош Дарваза в пятистах метрах от северных ворот Багча Дарваза, а также ворота Хазарасп Дарваза и Гандимьян Дарваза (рис. 2). Именно о внешнем городе Дишан-Кале пойдёт речь далее. К сожалению, Дишан Кала сохранилась намного хуже, чем Ичан-Кала. Стены Дишан-Калы имели десять ворот [1].

Согласно поэту и переводчику Агахию, оборонительная стена Дишан-Калы была возведена по инициативе Аллакулихана в 1842 году для защиты от набегов туркменских племён. Хан издал указ, чтобы каждый из его подчинённых проработал на месте грандиозного строительства ровно двенадцать дней в году, естественно, без соответствующего вознаграждения. С учётом того, что в подчинении у хана находилось более 200 тысяч человек, стена была возведена довольно быстро - при-

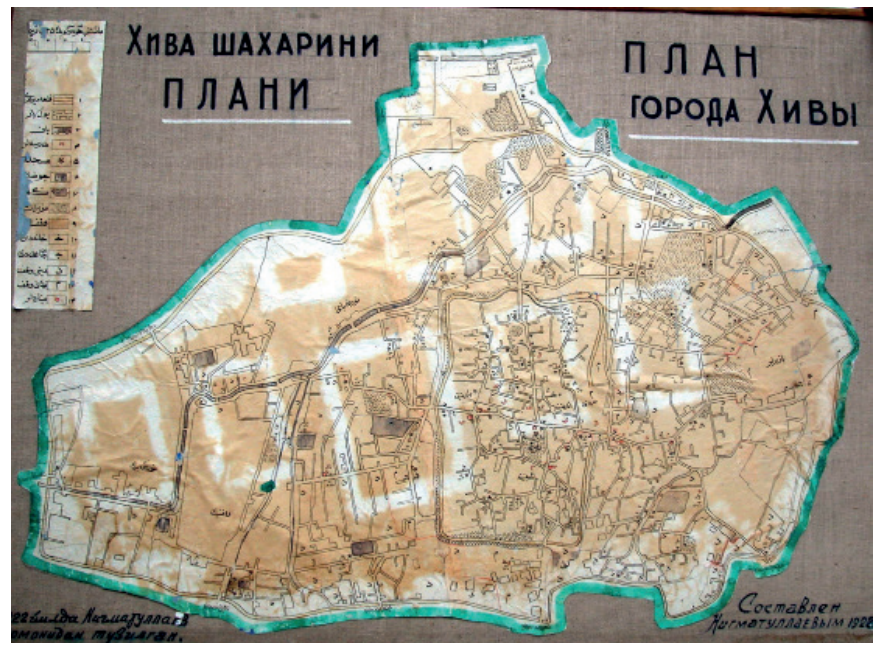

Рис. 1. План Ичан-Калы и Дишан-Калы, составленный инженером Нигматулаевым в 1922 году

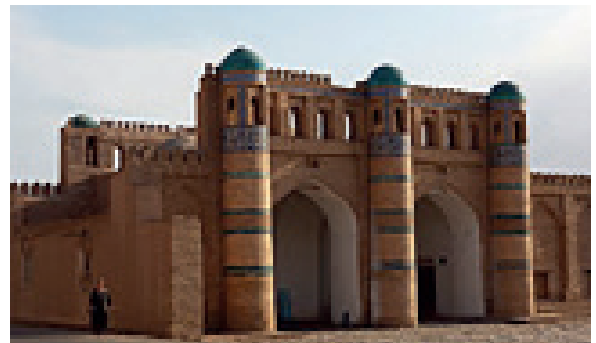

a)

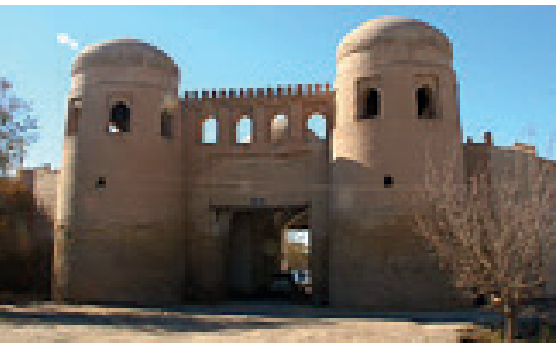

б)

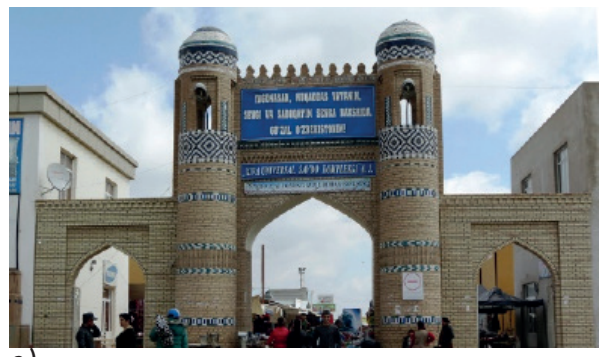

B)

Рuc. 2. Ворота Дишан-Калы: а) Кўша Дарвоза; б) Хазарасп Дарвоза; в) Гандимян Дарвоза 


\section{Год архитектуры и градостроительства стран СНГ}

мерно за месяц. Габариты внешнего вала были следующими: длина - 6615 м, высота - 6-8 метров, толщина у основания 4-6 м (рис. 3). Исследования показали, что глина была добыта в двух километрах севернее города, на территории, называемой Говук-куль; сейчас там большое озеро.

Стена Дишан-Калы была построена из высушенного на солнце глиняного кирпича - самана. Через равное, строго вымеренное расстояние из стены вырастали оборонительные башни. Верхняя часть по всей длине стены оканчивалась зубчатыми перилами с узкими амбразурами для удобства ведения боя. В качестве дополнительной защиты по периметру стены был вырыт ров, наполненный водой. С приходом ночи все ворота в город закрывались [2].

Ворота, ведущие в город, также являлись частью оборонительной системы. Они имеют по две ударные башни, каждая из которых расположена по разные стороны от арочных проездов, а над самими воротами находятся смотровые галереи.

В исторической части города Хивы сохранились традиционные жилые дома, расположенные на территории Ичан-Калы, которые также подлежат научно обоснованной реконструкции. Необходимость дифференцированного подхода к традиционной жилой застройке объясняется не только разной степенью её материальной сохранности и архитектурно-художественной ценности, но и различием визуальных взаимосвязей с рядовыми и монументальными памятниками архитектуры.

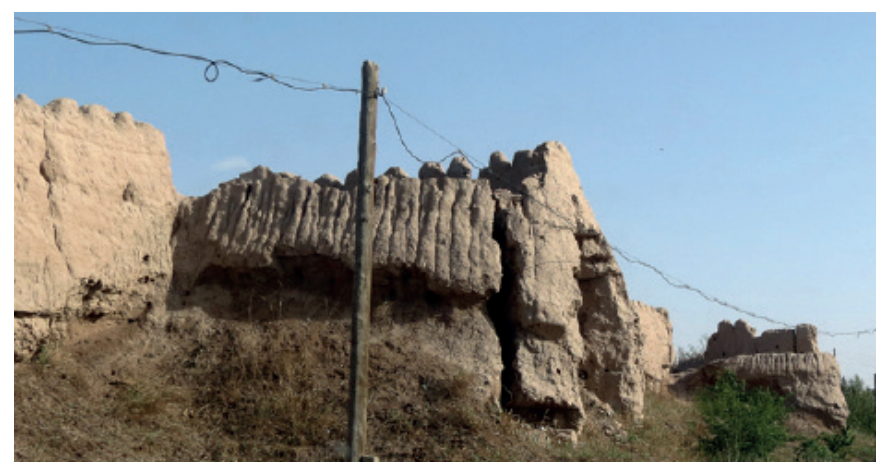

Pис. 3. Глиносырцовые стена Дишан-Калы

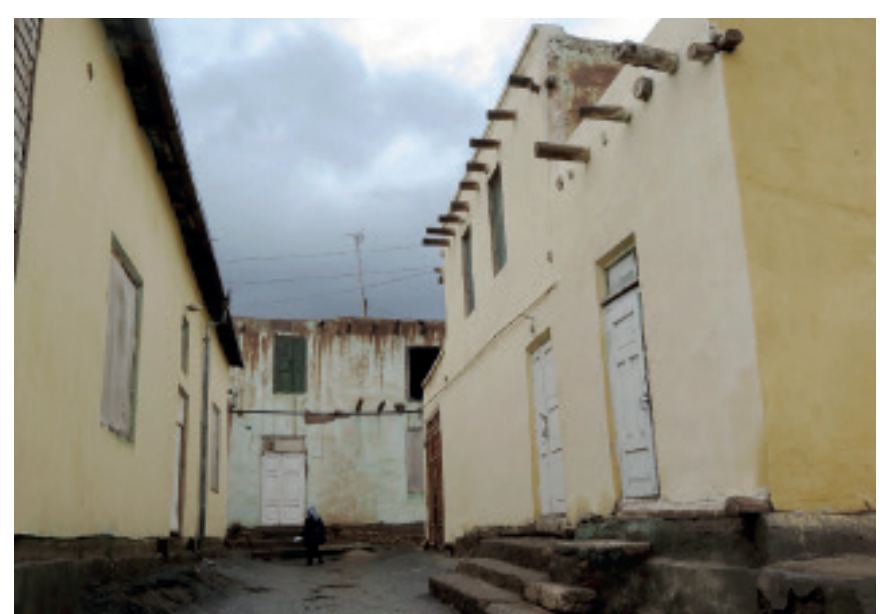

Рис. 4. Общий вид жилых домов на территории Дишан-Калы
Ценностные качества традиционной жилой застройки устанавливаются в результате проведения комплексных предпроектных исследований, которые охватывают вопросы сохранности планировочной структуры жилой застройки в исторической зоне города, типов жилой застройки, композиционных качества традиционных жилых домов и жилых кварталов, их инженерно-технического состояния.

Сохранность планировочной структуры традиционной жилой застройки устанавливается сравнением современных и старых топографических материалов, выявлением планировочных изменений, произошедших в старой городской застройке за последний период.

Укрупнённый подход к оценке сохранности планировочной структуры историко-заповедной территории города заключается в том, что постепенный процесс перепланировки традиционных жилых зданий (переделки фасадов, покрытий улиц, снос отдельных строений, строительство небольших зданий типа чайханы, павильонов для продажи сувениров) в данном случае не учитывается. Фиксируются зоны:

- существенной деформации, преобразования традиционной пространственно-планировочной структуры;

- частичной деформации пространственно-планировочной структуры заповедной зоны;

- сохранившейся пространственно-планировочной структуры [3].

При разработке проектов реконструкции жилых домов на территории Дишан-Калы, отражающих различные этапы развития города, в том числе состояние традиционной жилой застройки, целесообразно определить динамику преобразований исторически сложившейся планировочной структуры города и прокомментировать её (рис. 4).

Классификация типов традиционной жилой застройки заключается в нанесении на план исторической зоны жилых образований, принципиально отличающихся своей пространственно-планировочной ориентацией.

При современном проектировании сохраняют рациональное значение методы варьирования плотностей малоэтажной жилой застройки в зависимости от зон тяготения общегородского масштаба и расположения жилого дома по отношению к открытым пространствам. Композиционные качества традиционной жилой застройки охватывают широкий круг архитектурно-художественных и типологических особенностей народного жилья [4, с. 69].

Эстетические качества традиционной жилой застройки слагаются из характеристик фасадов отдельных жилых домов, композиционно-пространственной выразительности и запоминаемости улиц. Категории эстетической ценности фасадов жилых домов устанавливаются в натуре по следующим градациям: хорошо сохранившиеся оригинальные фасады; фасады с фрагментарной сохранностью первоначальных архитектурно-художественных достоинств жилого дома; фоновая архитектура; дисгармоничные, не представляющие архитектурно-художественной ценности. 
Критерии оценки вырабатываются коллегиально, опытным путём и требуют своего обоснования. Результаты обследований наносятся на план в условной системе обозначений.

Композиционно-пространственные качества старинных улиц слагаются из эстетических качеств отдельных жилых домов, однако часто они связаны с перспективами, сочетанием жилых строений с оазисными зонами. Потенциальная ценность фоновой застройки улиц часто состоит в том, что она подготавливает восприятие памятника архитектуры. Эти ценностные качества улиц должны определятся по результатам натурных обследований и наноситься на сводный план.

Архитектурно-типологическая ценность старинных жилых домов устанавливается с учётом сохранности первоначальной планировки, художественной отделки помещений (интерьеров) и конструкций, возраста жилого дома, строительного мастерства.

В основе оценки архитектурно-типологических качеств жилого дома должна быть, прежде всего, целостность и оригинальность его внутренней пространственно-планировочной композиции.

Методика установления категорий архитектурно-типологической ценности старинных жилых домов основана на натурном обследовании и экспертной оценке комиссии специалистов [5, с. 129].

Дома первой категории выделяются из всей массы старой городской жилой застройки. Это объекты, выдвигаемые на государственную охрану как памятники народного зодчества и подлежащие обмерам, фотофиксации и описанию в анкетахпаспортах, разработанных для инвентаризации памятников архитектуры Департаментом культурного наследия Министерства культуры Республики Узбекистан.

Среди домов первой категории желательно определить уникальные жилые дома, которые, независимо от своего положения в городе, не подлежат разборке или переделке.

Дома второй категории характеризуются фрагментарной сохранностью архитектурно-художественных элементов и состоят на учёте как резервы использования их архитектурных деталей при реконструкции аналогичных жилых комплексов. Результаты выявления ценностных качеств традиционных жилых домов (I и II категории) наносятся на сводный план и служат для установления градостроительной ценности традиционной жилой среды.

Форсированным методом выявления архитектурно-типологических ценностей традиционной жилой застройки, достаточным для разработки ПДП исторической зоны, является рекогносцировочное обследование в натуре старой городской жилой застройки с использованием сведений органов охраны памятников материальной культуры, старожилов, краеведов, городского управления архитектуры, выборочных схематических обмеров и нанесение на сводный план наиболее интересных в архитектурно-художественном отношении жилых домов.

Инженерно-техническое состояние одно-двухэтажных жилых домов местного типа характеризуется их общим высоким процентом амортизации, а также недолговечностью конструкций. Поэтому в процессе подведения итогов о ценностных историко-архитектурных качествах традиционной жилой застройки достаточны приближённые сведения о техническом состоянии жилых домов.

Таким образом, главным структурным изменением на территории Дишан-Калы в городе Хиве, подлежащей реконструкции, станет укрупнение градостроительного масштаба, в первую очередь, благодаря пробивке современных транспортных магистралей. Однако при реконструкции территории с жилой застройкой традиционного типа необходимо учесть ценные градостроительные традиции, такие как адаптированность к условиям окружающей среды, масштабность человеку, открытым пространствам и интенсивное использование исторической территории.

\section{Лuтратура}

1. Дишан-Кала [Электронный ресурс] // Википедия. Режим доступа: https://ru.wikipedia.org/wiki/Дишан-Кала (дата обращения 07.04.2021).

2. Официальный сайт компании «Central Asia Travel» [Электронный ресурс]. - Режим доступа: info@centralasiatravel.com (дата обращения 22.04.2021)

3. Салимов А.М. Сохранение и использование памятников архитектуры Узбекистана / А.М. Салимов. - Ташкент : Фан, 2009. - 290 c.

4. Салимов А.М. Приспособление комплексов-памятников историко-архитектурного заповедника «Ичан-Кала» для современных нужд / А.М. Салимов // Архитектура. Строительство. Дизайн. - 2010. - № 1. - С. 69-73.

5. Белоусов В.Н. Реконструкция центров исторических городов / В.Н. Белоусов, Н.Н. Бочарова, В.А. Васильченко. - М. : Стройиздат, 1987. - 224 С.

\section{References}

1. Dishan-Kala. Vikipediya [Wikipedia]. Access mode: https://ru.wikipedia.org/wiki/Dishan-Kala (Accessed 04/07/2021). (In Russ.)

2. Ofitsial'nyi sait kompanii «Central Asia Travel» [The official website of the "Central Asia Travel" company]. Access mode: info@centralasia-travel.com (Accessed 22.04.2021). (In Russ.)

3. Salimov A.M. Sokhranenie $i$ ispol'zovanie pamyatnikov arkhitektury Uzbekistana [Preservation and use of architectural monuments of Uzbekistan]. Tashkent, Fan Publ., 2009, 290 p. (In Russ.)

4. Salimov A.M Prisposoblenie kompleksov-pamyatnikov istoriko-arkhitekturnogo zapovednika «Ichan-Kala» dlya sovremennykh nuzhd [Adaptation of the complexes-monuments of the historical and architectural reserve "Ichan-Kala" for modern needs]. In: Arkhitektura. Stroitel'stvo. Dizain [Architecture. Consruction. Design], 2010, no. 1, pp. 69-73. (In Russ.)

5. Belousov V.N., Bocharova N.N., Vasil'chenko V.A. Rekonstruktsiya tsentrov istoricheskikh gorodov [Reconstruction of the centers of historical cities]. Moscow, Stroiizdat Publ., 1987, 224 p. (In Russ.) 


\section{Год архитектуры и градостроительства стран СНГ}

Дурдиева Гавхар Салаевна (Хива). Доктор архитектуры, старший научный сотрудник. Руководитель лаборатории Хорезмской академии Мамуна (220900, Республика Узбекистан, Хорезмская область, Хива, Марказ-1. Хорезмская академия Мамуна). Эл.почта: gavhar61@mail.ru.

Заргаров Адилбек Камилович (Хива). Старший научный сотрудник Хорезмской академии Мамуна (220900, Республика Узбекистан, Хорезмская область, Хива, Марказ-1. Хорезмская академия Мамуна). Эл. почта: zargarov1960@mail.ru.

Рустамов Исломбек Одилбекович (Хива). Младший научный сотрудник Хорезмской академии Мамуна (220900, Республика Узбекистан, Хорезмская область, Хива, Марказ-1. Хорезмская академия Мамуна). Эл. почта: mamunuz@yandex.com.

Дусчанов Шерзод Шамуродович (Хива). Аспирант Хорезмской академии Мамуна (220900, Республика Узбекистан, Хорезмская область, Хива, Марказ-1. Хорезмская академия Мамуна). Эл. почта: duschanov.sherzod@mail.ru.

Durdieva Gavkhar S. (Khiva). Doctor of Architecture, Senior Researcher. Head of thelaboratory at Khorezm Mamun Academy (Markaz-1, Khiva, Khorezm, Republic of Uzbekistan, 220900. Khorezm Mamun Academy). E-mail: gavhar61@mail.ru.

Zargarov Adilbek K. (Khiva). Senior Researcher at Khorezm Mamun Academy (Markaz-1, Khiva, Khorezm, Republic of Uzbekistan, 220900. Khorezm Mamun Academy). E-mail: zargarov1960@mail.ru.

Rustamov Islombek 0. (Khiva). Junior Researcher at Khorezm Mamun Academy (Markaz-1, Khiva, Khorezm, Republic of Uzbekistan, 220900. Khorezm Mamun Academy). E-mail: mamunuz@yandex.com.

Duschanov Sherzod Shamurodovich (Khiva). Postgraduate student at Khorezm Mamun Academy (Markaz-1, Khiva, Khorezm, Republic of Uzbekistan, 220900. Khorezm Mamun Academy).E-mail: duschanov.sherzod@mail.ru. 